\title{
DINÂMICAS DE EDUCAÇÃO AMBIENTAL PARA VALORIZAÇÃO DOS RECURSOS FLORESTAIS APLICADAS AO ENSINO FUNDAMENTAL
}

Marjana Machado dos Santos ${ }^{1}$ Damáris Gonçalves Padilha²

Resumo: O presente estudo buscou aplicar ações de educação ambiental para valorização dos recursos florestais no âmbito escolar, sendo que nos últimos anos a Educação Ambiental (EA), tem sido uma ferramenta de suma importância nas discussões e intervenções entre o ser humano e o seu ambiente. Objetivou-se sensibilizar alunos da Escola de Ensino Fundamental Padre Nóbrega, localizada no município de Santa Maria (RS), com relação à importância dos recursos florestais, através de atividades, no modo de informar questões conceituais, valorativas, informativas e críticas sobre a temática. Os resultados adquiridos neste trabalho demonstram a importância de inserirmos os temas relacionados aos recursos florestais nas turmas de ensino fundamental, fortalecendo ainda mais a construção de uma sociedade ambientalmente consciente e saudável.

Palavras-chave: Sensibilização; Recursos Florestais; Educação Ambiental; Ensino Fundamental.

Abstract: The present study sought to apply environmental education actions to enhance forest resources in the school environment, and in recent years Environmental Education (EA) has been an extremely important tool in discussions and interventions between human beings and their environment. The objective was to sensitize students of the Padre Nóbrega Elementary School, located in the city of Santa Maria (RS, Brazil), regarding the importance of forest resources, through activities, in order to inform conceptual, evaluative, informative and critical issues on the theme. The results acquired in this work demonstrated the importance of inserting the themes related to forest resources in the classes of elementary school, further strengthening the construction of an environmentally conscious and sustainable society.

Keywords: Awareness; Forest Resources; Environmental Education; Elementary School.

1 Universidade Federal de Santa Maria. E-mail: marjanamachado@gmail.com

2 Universidade Federal de Santa Maria. E-mail:damaris.padilha@ufsm.br 


\section{Introdução}

Todas as ações e iniciativas voltadas a Educação Ambiental (EA) são de grande valia no processo educativo, sendo uma proposta para a construção de um novo pensar e agir dos estudantes, de uma forma que provoque a sensibilização, e a mudança nas atitudes relacionadas à interação homemnatureza. Trabalhar com dinâmicas de educação ambiental no ensino fundamental, como um instrumento de sensibilização e reflexão sobre valorização dos recursos florestais, tem como intuito difundir esse conhecimento, em prol de uma mudança comportamental perante os recursos naturais e o ambiente que nos cerca.

De acordo com Effting (2007), a Educação Ambiental (EA) é um método de aprendizagem, que visa o gerenciamento e o melhoramento das relações entre o homem e a natureza de uma forma integrada e sustentável.

Desta forma, introduzir a EA nas instituições de ensino torna-se essencial, pois trata-se de uma gestão integrada do ambiente com a sociedade (MEDEIROS et al., 2011), sendo que, por meio da educação é possível promover à reflexão desses indivíduos sobre as interações ecológicas com o ambiente que o cercam, como por exemplo, à vida humana, a fauna, a flora, aos rios e às florestas.

Diante disso, cabe destacar que as florestas não nos propiciam apenas produtos e subprodutos comuns do nosso cotidiano, como a madeira, o carvão, os óleos essenciais, o papel etc., mas também, diversos benefícios advindos dos diferentes serviços ambientais, como a sistematização do ciclo hidrológico, o controle da erosão e da qualidade do solo, a conservação da biodiversidade, fornecimento de oxigênio para o planeta, e a contribuição na diminuição dos impactos das mudanças climáticas.

Segundo Oliveira (1998), para melhor compreendermos essas relações entre o homem e a natureza, devemos ter claro o pensamento de que as florestas são uma fonte de recurso natural renovável, e que a sua exploração ordenada pode gerar inúmeros bens e produtos, constituindo assim um papel importantíssimo no fator de crescimento socioeconômico. Ressalta-se ainda, a sua importância vital para o equilíbrio ecológico sendo considerado um patrimônio vivo e rico da biodiversidade.

Associado aos benefícios proporcionados pelas florestas está à preocupação em relação aos impactos ambientais causados pelo aumento populacional desordenado, a poluição do solo, da água e do ar, que consequentemente acabam por afetar de forma direta e indiretamente a qualidade ambiental dos ecossistemas florestais afetando também a futura disponibilidade desses recursos.

Nesse sentido, a prática da educação ambiental inserida na realidade atual dos alunos do ensino fundamental pode causar um efeito multiplicador e sensibilizador ao tema, imprimindo uma reflexão mais profunda no ambiente escolar. 
Sendo assim, o trabalho proposto visa sensibilizar diretamente os educandos envolvidos, sobre a importância dos recursos florestais, por meio da educação ambiental, visando promover a interação e o despertar destas, para práticas mais sustentáveis e para o convívio equilibrado entre o ser humano e o ambiente, dentro e fora do ambiente escolar.

\section{Material e Métodos}

O presente estudo foi parte integrante de um projeto de extensão universitária e foi realizado na Escola Municipal de Ensino Fundamental Padre Nóbrega, localizada no bairro Nossa Senhora das Dores, no município de Santa Maria (RS). As ações de educação ambiental voltadas à temática da valorização dos recursos florestais foram desenvolvidas por meio de três (3) atividades temáticas, divididas em: caixa sensorial, painel com a identificação das espécies localizadas no pátio da escola e levantamento das espécies em torno da escola. Participaram das oficinas, alunos entre seis (6) e doze (12) anos de idade, integrantes do primeiro ao quinto ano do ensino fundamental da rede pública municipal.

Depois de realizada as atividades, cada participante recebeu um questionário (pode ser visualizado em Santos, 2019) com perguntas sobre a dinâmica realizada, e em seguida elaboravam uma ilustração com o propósito de expressar o seu entendimento sobre o tema abordado.

As atividades foram executadas de abril a junho de 2019, sendo realizadas duas vezes por semana em um período de aproximadamente 3 horas e 15 minutos para cada atividade.

\section{Caixa sensorial - elementos que constituem uma árvore}

Essa dinâmica consistiu em uma análise sensorial referente aos elementos que compõem a estrutura de uma árvore, como por exemplo, galhos, sementes, folhas, casca de árvores, frutos, raízes, e teve o propósito de sensibilizar as crianças ao tocarem nos elementos que estavam presentes no interior das caixas, e assim explorá-los com o sentido do tato.

Para à execução da atividade, os alunos foram organizados em 5 (cinco) grupos, nos quais as caixas, foram distribuídas uma para cada grupo, e cada componente do grupo tinha a oportunidade de sentir o elemento que havia no seu interior. No momento em que todos os alunos do grupo tinham finalizado a análise do elemento que continha na caixa, esta passava então para o grupo seguinte, realizando assim, o rodízio das 5 (cinco) caixas por todos os grupos.

Cada caixa sensorial apresentava algum elemento arbóreo, sendo que os materiais utilizados na atividade foram: sementes das espécies de vassourão-branco (Vernonanthura discolor (Spreng.) H.Rob), cedro (Cedrela fissilis Vell.), e jerivá (Syagrus romanzoffiana (Cham.) Glassman); casca da espécie angico-vermelho (Anadenanthera macrocarpa (Benth.) Brenan); folhas 
das espécies ipê-amarelo (Handroanthus chrysotrichus (Mart. ex DC.) Mattos), goiabeira (Psidium guajava Linnaeus, Carl von) e ameixeira (Eriobotrya japonica (Thunb.) Lindl.). Após a análise de todos os alunos referente aos elementos apresentados, foram abertas as caixas sensoriais, e apresentados os elementos um a um. Em seguida, foi solicitado a eles que expressassem seu entendimento sobre a importância das árvores, e o que sentiram ao realizar a prática sensorial, na forma de desenhos.

Os materiais necessários para realizar da atividade foram: 5 caixas de papelão com dimensões mínimas de $20 \times 30 \times 10 \mathrm{~cm}$; elementos naturais de uma árvore como: sementes, folhas, galhos, suficientes para que seja possível encher a mão da criança; folhas A4; tinta guache colorida ou giz de cera.

A dinâmica foi aplicada com os alunos do $1^{\circ}$ ao $3^{\circ}$ ano do ensino fundamental.

\section{Painel com a identificação das espécies localizadas dentro da escola}

A dinâmica objetivou reconhecer as espécies arbóreas localizadas no pátio da escola, tendo como proposito elaborar painéis com diferentes materiais coletados das árvores identificadas. A presente atividade visou ensinar os alunos algumas características utilizadas na identificação das espécies arbóreas, destacando a importância da arborização que os cercam.

Desse modo, à execução da atividade teve como proposta levar as crianças para uma caminhada no pátio da escola, no intuito, de realizar o reconhecimento das espécies existentes e coletar material útil para a construção dos painéis arbóreos, que foram confeccionados pelos alunos, juntamente com a identificação dos indivíduos observados.

Quanto à confecção dos painéis, foram utilizados elementos coletados das árvores, como por exemplo, ramos, folhas e a casca de cada espécie identificada, para posteriormente serem coladas na cartolina, com o desenho realizado pelos alunos, para apresentar a leitura dos mesmos em relação aos indivíduos arbóreos presentes na escola. A atividade foi aplicada aos alunos das duas turmas do $4^{\circ}$ ano do ensino fundamental.

\section{Levantamento das espécies arbóreas em torno da escola}

A atividade prática teve como objetivo o reconhecimento das espécies arbóreas localizadas no entorno da escola, realizando um levantamento a campo com as crianças. A atividade visou introduzir aos alunos na prática da identificação das espécies arbóreas, salientando a importância de observaras suas características e peculiaridades.

Sendo assim, a dinâmica consistiu em despertar nas crianças o interesse e a curiosidade em conhecer a vegetação pertencente à arborização das ruas da cidade em que residem, e, em aprender os elementos básicos e necessários para a realização de um levantamento arbóreo. 
A execução da dinâmica teve como proposta levar as crianças para uma caminhada ao entorno da escola, coletar informações e medidas dos indivíduos arbóreos e assim, realizar o levantamento dos mesmos.

No momento da saída para a rua, os alunos foram divididos em grupos, onde, cada grupo teve um integrante responsável para as anotações e dois para realização das medições.

Para o levantamento florístico foram analisadas as seguintes variáveis de cada indivíduo: altura da árvore, circunferência a altura do peito (CAP), área de copa, tipo de tronco, distância entre indivíduos, distância entre a árvore e o muro residencial, se havia floração ou fruto, tipo de fruto, se havia folha e qual era o tipo de folha, se era uma espécie nativa do RS ou exótica, se havia danos no indivíduo arbóreo, se havia a presença de fauna e se havia a presença de pragas, como formigas, ácaros, etc. Também foram analisadas variáveis do ambiente onde se encontravam as árvores, tais como: a largura da calçada e o tipo de pavimentação do calçamento,

Em relação aos materiais utilizados para atividade prática foram: ficha avaliativa do levantamento florístico (disponibilizada uma por grupo); trenas de costura e métrica; lápis; borracha; giz de cera ou lápis de cor; folha A4. A atividade prática foi realizada com os alunos do $5^{\circ}$ ano do ensino fundamental.

\section{Resultados e Discussões}

No total foram cento e noventa e sete (197) crianças que participaram das atividades propostas nesse estudo, sendo turmas do primeiro ao quinto ano do ensino fundamental.

\section{Caixa sensorial - elementos que constituem uma árvore}

A dinâmica foi aplicada nas turmas do primeiro ao terceiro ano do ensino fundamental, perfazendo um o total de cento e dezesseis (116) alunos participantes na atividade, sendo duas turmas de cada ano.

Em um primeiro momento em sala de aula foi solicitado aos alunos que participassem de forma oral, descrevendo quais seriam as partes que constituem uma árvore, e conforme a descrição dos mesmos foi elaborado um desenho no quadro negro (Figura $1 \mathrm{~A}$ ), fortalecendo assim, a contextualização sobre a temática abordada, e permitindo terem um registro da atividade no seu caderno (Figura 1B). 

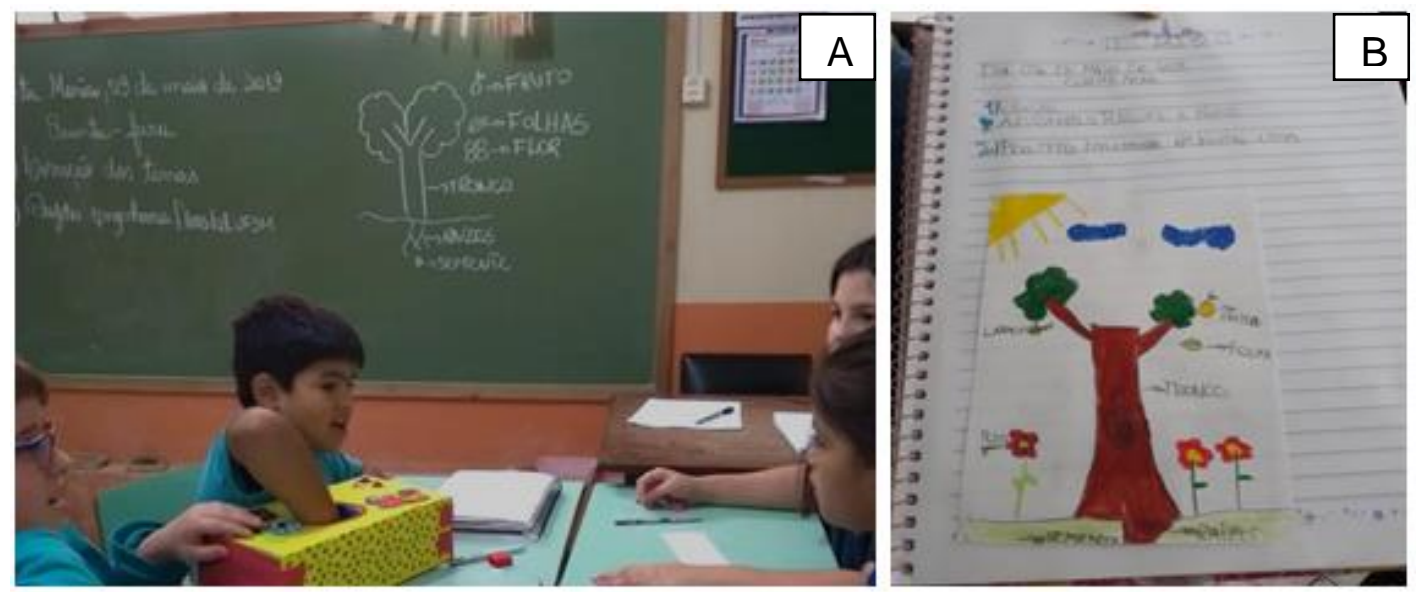

Figura 1: A) Desenho no quadro negro com alguns elementos que constituem uma árvore.

B) Representação dos elementos realizada por um aluno no seu caderno.

Fonte: Autoras (2019).

Ao final da atividade, distribui-se um questionário de oito (8) questões (pode ser visualizado em Santos, 2019), as quais foram voltadas a percepção dos alunos quanto à importância das árvores nas nossas vidas. Assim, estes foram questionados, por exemplo, sobre gostar ou não de realizar a atividade da caixa sensorial, no qual $95 \%$ deles responderam que sim e apenas $5 \%$ disseram que não gostaram da atividade (6 alunos). No entanto, quando questionados se gostariam de realizar mais atividades práticas como esta, sobre a importância das florestas, $100 \%$ dos participantes responderam que gostariam.

Em seu trabalho Pfeifer et al. (2016), relataram que 75\% dos alunos demostraram satisfeitos ao realizar a atividade da trilha sensitiva proposta pelos autores, fortalecendo a ideia que este modelo de dinâmica sensorial, seja trilha ou caixa sensorial, apresentam uma considerável aceitação por parte dos educandos uma vez que os sensibilizam em algum momento da atividade.

Muito além apenas da aceitação pela atividade Matarezi (2001), destaca que os estudos sobre experimentos que ocultam a visão despertam para que os outros sentidos sejam potencializados e aguçados, provocando assim uma profunda reflexão nos participantes, com as inter-relações entre sociedade e natureza no tempo e espaço. Sendo esta uma premissa de fundamental importância para formação socioambiental do indivíduo, principalmente na idade da primeira infância.

De acordo com Oliveira e Vargas (2009) a construção do conhecimento passa pela percepção do meio através dos sentidos e das sensações, sendo assim, os sentidos são de suma importância para a relação do indivíduo com o meio em que vive.

$\mathrm{Na}$ atividade da caixa sensorial o principal sentido explorado foi o tato, 
explorar outros sentidos, principalmente quando suprime a visão (fica sem ela) defende-se bem com o sentido tato, estabelecendo assim contato com os objetos a serem identificados.

Neste sentido, ao aproximar as crianças dos elementos arbóreos, buscou-se que eles estimulem e/ou fortaleçam sua consciência ambiental, ao passo que se aproximam da compreensão estrutural e a dinâmica ecológica que formam nossas florestas.

Também foi possível observar a compreensão atribuída pelas crianças quando questionadas sobre a importância das árvores na sua vida. Observouse que $65 \%$ dos alunos, associaram a importância das árvores com ar, respiração e oxigênio, $9 \%$ das crianças relataram que as árvores são importantes para natureza e para o meio ambiente de forma genérica, $9 \%$ associaram sua importância com a produção de frutas para o consumo, e que $8 \%$ relacionaram a sua importância "para viver".

Cabe destacar que apenas 3\% dos alunos relacionaram a questão das florestas com a produção de papel ou outro material de consumo de origem vegetal, confirmando a necessidade da inserção de atividades escolares que propiciem a compreensão por parte das crianças a respeito de todos os serviços ecossistêmicos que podem ser gerados pelas florestas.

Apenas $4 \%$ dos alunos consideraram importante o plantio de árvores, entretanto, quando questionados sobre a importância de plantar árvores na sua cidade ou escola, cento e quinze (115) crianças responderam que sim, que consideram essa atividade importante e apenas uma (1) considerou não ser importante.

Outro dado interessante observado pelo questionário foi o número de alunos que descreveram ter árvores em suas residências. Observa-se que $84 \%$ das crianças têm árvores em seus lares e apenas 16\% responderam não ter nenhuma árvore em sua residência. Esse resultado pode ser em razão da escola estar localizada em um bairro residencial, onde há poucas residências em formato de apartamentos ou condomínios verticais, sendo em maioria residências do tipo casa, o que em geral, favorece que ocorra o plantio de árvores na área de pátio, seja com o objetivo de sombra, frutífera ou ornamental.

Além dos questionários, esta atividade buscou avaliar os participantes por meio de desenhos, observando sua forma de expressão e a sensibilização a respeito da atividade proposta, pois, segundo Junior et. al (2016) as ilustrações (os desenhos) são uma ferramenta utilizada pelas crianças para expressar concretamente o conhecimento sobre o ambiente que a cerca.

Os autores expõem ainda, que os desenhos são uma forma que as crianças utilizam para dizer algo sobre as coisas, e que ainda podem ser usados como um instrumento valioso no cotidiano dos professores, pois através da interpretação das ilustrações dos alunos podem-se obter resultados que auxiliarão no desenvolvimento da aprendizagem. 
Também se pode observar as diferentes leituras e compreensões expressas pelos alunos das diferentes turmas e idades, as quais participaram dessa atividade. Em alguns casos os alunos se expressaram desenhando os elementos que estavam dentro de alguma das caixas sensoriais apresentadas.

É compreensível que as crianças do primeiro ano (seis a sete anos de idade) não apresentam ainda, uma expressão mais crítica e reflexiva, pois estão ainda no processo de conhecer e compreender noções básicas sobre o meio ambiente, em especial os recursos florestais, os quais para alguns são temas ainda não abordados curricularmente.

Porém, ao analisar os alunos do segundo e o terceiro ano do ensino fundamental, observou-se que estes realizaram uma leitura diferente dos do primeiro ano, onde, expressaram em seus desenhos vários dos elementos apresentados nas dinâmicas e no questionário como, por exemplo, desenhos de banco de praça, lixeiras, árvores, a presença de fauna, nuvens, rios, e flores, resultando em ilustrações de paisagens e não apenas de um elemento individual. Logo, percebeu-se que nesta idade (oito a nove anos), as crianças já apresentam um entendimento sobre a formação de parques, praças, florestas e bosques, bem como a sua importância.

Um exemplo pôde ser observado na representação dos elementos de um parque (Figura $2 \mathrm{~A}$ ) onde há a presença de uma lixeira, flores, árvores e arbustos, demostrando que já existe uma compreensão por parte da criança, dos diferentes elementos ambientais, pertencentes àquele local, assim como a preocupação com seu cuidado (resíduos).

$\mathrm{Na}$ Figura 2B notou-se também que há essa compreensão, porém, a criança expressou ainda, à relação dos elementos da floresta com a atividade sensorial proposta, quando apresentou, na ilustração, um bosque com cachoeira e com a presença de aves (parte superior), e na parte inferior, desenhou uma menina (no caso a própria criança) com algumas caixas, que simbolizavam a atividade realizada.

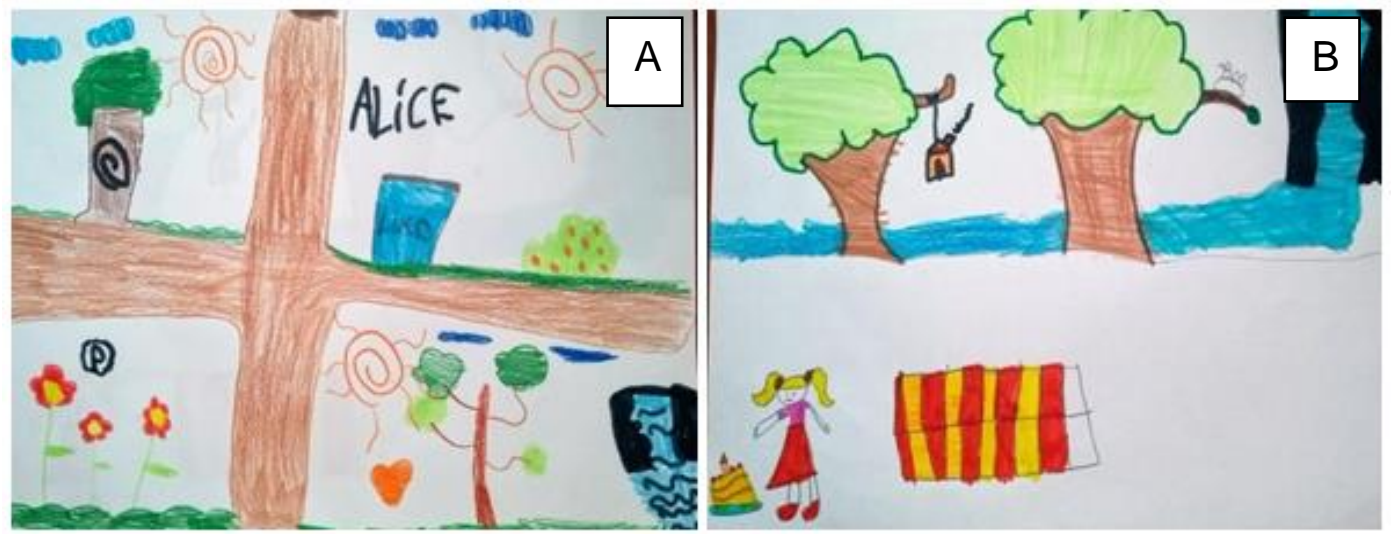

Figura 2: Exemplo de ilustração sobre a atividade, realizada pelos alunos do segundo ano do ensino fundamental. A) Representação de elementos naturais e antrópicos. B) Representação dos elementos da floresta e vistos na atividade.

Fonte: Autoras (2019). 
Este resultado assemelha-se ao estudo realizado por Ávila et al. (2009) os quais também observaram nos desenhos das crianças elementos antrópicos, como por exemplo, resíduos, animais, casas, plantas e o próprio ser humano, incluindo ainda elementos como água, flora e fauna dispondo assim, a concepção de ambiente. Porém, os autores observaram que $62 \%$ dos alunos restringiram seus desenhos e representações com elementos naturais, diferente do observado neste estudo, onde apenas 35\% representaram apenas elementos naturais, e $65 \%$ apresentaram em seus desenhos elementos naturais associados aos elementos antrópicos, inclusive se inserindo ao meio representado.

Este resultado destaca a importância da inserção de atividade de educação ambiental no ambiente escolar, principalmente nos primeiros anos de formação da criança. Ao comparar alguns resultados obtidos por Ávila et al. (2009) com os alcançados neste estudo, podemos observar que em 10 anos os educandos mudaram sua forma de compreender o meio ambiente, não considerando apenas elementos naturais como constituintes destes, mas agora, se sentem "totalmente" integrantes ao meio, fortalecendo assim, os objetivos de despertá-los para a compreensão de que eles fazem parte e são responsáveis pelo ambiente que os cercam.

Quando a atividade foi aplicada para o terceiro ano foi possível observar, no momento da identificação dos elementos, uma maior facilidade em identificar cada um dos elementos, como também, uma maior agilidade e rapidez no decorrer da atividade, quando comparado com os alunos do primeiro e o segundo ano, e ainda verificou-se que a caixa sensorial foi relativamente fácil para os alunos desta faixa etária.

Também se observou que conforme variou a idade e o nível escolar dos participantes, a percepção e compreensão dos alunos sobre o tema proposto foi diferenciado, em virtude de estarem sendo estimulados sobre o assunto há mais tempo (no ambiente familiar ou escolar), assim como, pelo fato de suas habilidades cognitivas aumentarem com o passar do tempo. Em seus estudos Edgar Morin (2008), Paulo Freire (2007), Lev S. Vygotsky (1989) e Jean Piaget (1982), afirmam que a dinâmica em grupo, promove e auxilia o processo de construção da aprendizagem do educando, e no desenvolvimento da interação entre as crianças e crianças/adulto, de uma forma lúdica e significativa.

Quanto aos elementos que acharam difícil de identificar na caixa sensorial, $48 \%$ relataram o elemento sementes, totalizando os 56 alunos participantes do primeiro ao terceiro ano, mostrando um valor plausível, pois havia sementes de três espécies diferentes, que variavam em tamanho, densidade e textura, aumentando assim o grau de dificuldade de análise pelas crianças.

Em relação, aos outros elementos, 19\% responderam que a maior dificuldade foi à identificação do elemento folha, seguida da casca com $13 \%$. Cerca de $10 \%$ dos participantes consideram todos os elementos difíceis de

Revista brasileira educação ambiental 
serem identificados pelo tato e $5 \%$ deles consideram que nenhum elemento foi difícil. Foi possível realizar também uma análise dos resultados separadamente por série (Tabela 1), na qual notou-se, que os alunos do segundo e terceiro ano consideraram como o elemento mais difícil de identificar como sendo a semente com $60 \%$ e $68 \%$ respectivamente.

Tabela 1: Percentagem dos elementos considerados pelos alunos como os mais difíceis de identificar, conforme a série indicada.

\begin{tabular}{|c|c|c|c|}
\hline Elementos & $\mathbf{1}^{\mathbf{0}}$ ano & $\mathbf{2}^{\mathbf{0}}$ ano & $\mathbf{3}^{\mathbf{0}}$ ano \\
\hline Semente & $20 \%$ & $60 \%$ & $68 \%$ \\
\hline Folha & $38 \%$ & $10 \%$ & $9 \%$ \\
\hline Casca & $20 \%$ & $10 \%$ & $9 \%$ \\
\hline Todos & $8 \%$ & $12 \%$ & $12 \%$ \\
\hline Nenhum & $13 \%$ & $3 \%$ & $0 \%$ \\
\hline Folha e Semente & $3 \%$ & $5 \%$ & $0 \%$ \\
\hline Casca e Semente & $0 \%$ & $2 \%$ & $3 \%$ \\
\hline
\end{tabular}

Fonte: Santos (2019).

Já o primeiro ano apresentou $20 \%$ para esse elemento, pois descreveram o elemento folhas (38\%) como sendo o mais difícil de identificar. Uma razão para este resultado foi que a semente da espécie cedro (Cedrela fissilis Vell.), acabou confundindo-os na identificação, devido a sua forma, estrutura e textura, as quais os alunos consideraram muito semelhante, segundo eles, ao de uma "folha pequena".

No caso das turmas dos primeiros anos, a maior dificuldade observada, foi no momento da identificação do elemento folha, da espécie de goiabeira (Psidium guajava $\mathrm{L}$ ), em razão da sua textura e rigidez, assim como a pouca familiaridade dos alunos com a sensação sentida no momento da atividade, a maioria desses participantes não soube dizer qual era o elemento na caixa.

Ao final da aplicação do questionário, realizou-se uma discussão sobre as partes elementares das árvores, a importância de cada uma, ressaltando seus benefícios tanto ambientais como sociais e econômicos. Muitas crianças ficaram surpresas em saber que das árvores podem ser fabricados vários produtos, a exemplo de alguns cosméticos, remédios, produtos de limpeza, bolos etc.

Por fim, realizou-se com os alunos uma discussão sobre como nós empreendermos que somos parte integrante do meio ambiente é fundamentam para garantirmos a sua preservação, assim como, o papel importante que a escola e a família têm na formação socioambiental das crianças, destacando que pequenas atitudes podem fazer a diferença para garantir um futuro de sustentabilidade ambiental. 


\section{Confecções dos painéis das espécies arbóreas identificadas no pátio da escola}

A dinâmica foi aplicada nas turmas do quarto ano do ensino fundamental, perfazendo um total de quarenta e um (41) alunos que participaram da atividade. Para realização desta atividade, em um primeiro momento, em sala de aula, foi explicado aos alunos o que seria realizada na atividade externa (no pátio da escola).

Primeiramente realizou-se uma caminhada pelo pátio (Figura 4) para que os alunos pudessem observar, tocar, analisar e identificar as árvores existentes no local.

Neste momento, buscou-se ressaltar alguns elementos e técnicas que podem ser utilizadas na identificação de uma árvore, como por exemplo, o cheiro e a cor das folhas, a textura de casca, o tipo de casca, o tipo e formato das folhas, e as flores, frutos e sementes quando presentes. Além disso, o reconhecimento das espécies também foi realizado com a perspectiva de se conhecer a realidade onde os alunos estão inseridos para incentivar a sua preservação e cuidado.

Também foi destacado sobre os cuidados que devemos ter com a manutenção das árvores, como por exemplo, a importância da realização correta do plantio e da poda. Além disso, buscou-se contextualizar brevemente sobre as autorizações e os órgãos competentes para execução dessas atividades, os cuidados fitossanitários necessários para boa condução e sanidade das plantas, as predações, e por fim, destacou-se a importância que as árvores têm para a fauna, flora e para a sobrevivência do homem.

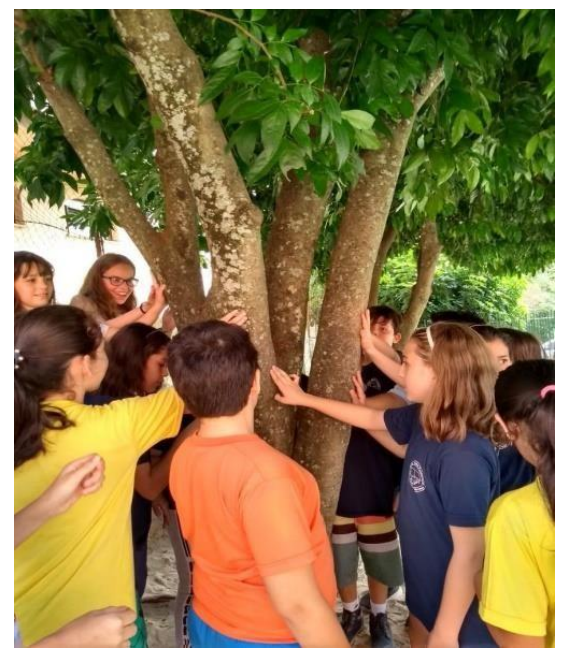

Figura 4: Caminhada de observação e identificação das árvores no pátio da escola, com os alunos do quarto ano do ensino fundamental. Fonte: Autoras (2019).

A escola não apresentava grande quantidade nem diversidade arbórea no pátio, sendo encontradas no local, árvores nativas como o Inga marginata Willd. (Ingá), Eugenia uniflora L.(pitangueira), Ipê-amarelo (Handroanthus 
chrysotrichus (Mart. ex DC.) Mattos), e na parte externa em frente a escola havia indivíduos da espécie exótica extremosa (Lagerstroemia indica (L.) Pers.).

Durante a caminhada de observação e identificação das árvores optouse por trabalhar com as espécies de Inga marginata Willd. (Ingá) e Eugenia uniflora L.(pitangueira), em razão da pouca diversidade de indivíduos e espécies, conforme mencionado. Foi realizada a coleta do material a serem utilizado na confecção dos painéis de forma ordenada e cuidadosa para evitar possíveis danos aos indivíduos, o material (folhas, galhos, casca) foi coletado utilizando ferramentas próprias para esta finalidade.

Neste contexto, destaca-se o estudo de Barros (2018 apud RAMBO, 2019) o qual relata a importância de oferecer alguns materiais (elementos) naturais para as crianças, com o propósito de servirem como ferramentas lúdicas, como por exemplo, materiais não estruturados (cascas, sementes, restos de madeiras), elementos naturais e brinquedos de madeira.

Visto que cada um desses materiais remete uma sensação diferente nas crianças, principalmente ao tato e ao cheiro, entende-se que essa aproximação e o contato com os elementos naturais os quais estão presentes na sua rotina diária poderão contribuir na formação de ideias, na sensibilização, na construção do conhecimento sobrea relação homem/natureza.

Os educandos demonstraram interesse em conhecer as árvores e grande curiosidade em aprender os elementos de identificação das espécies. Após a coleta de materiais de ambas as espécies supracitadas, iniciou-se em sala de aula, a confecção dos painéis. Para isso, os alunos foram divididos em grupos de cinco (5), ambos com os materiais das diferentes as espécies.

$\mathrm{Na}$ Figura 5 pode-se observar que os alunos optaram por confeccionar apenas a espécie de ingá, já na Figura B5 as crianças representaram as duas espécies em seu painel. Nota-se que ambos os grupos identificaram as partes das árvores, as quais foram comentadas na caminhada de observação e identificação das espécies dentro do pátio da escola. Desse modo, ao deixar que a criança brinque com os elementos oriundos da natureza, auxilia no criar, montar e construir, possibilitando assim o desenvolvimento de habilidades motoras, e nas relações com o ambiente a sua volta (BARROS, 2018). 

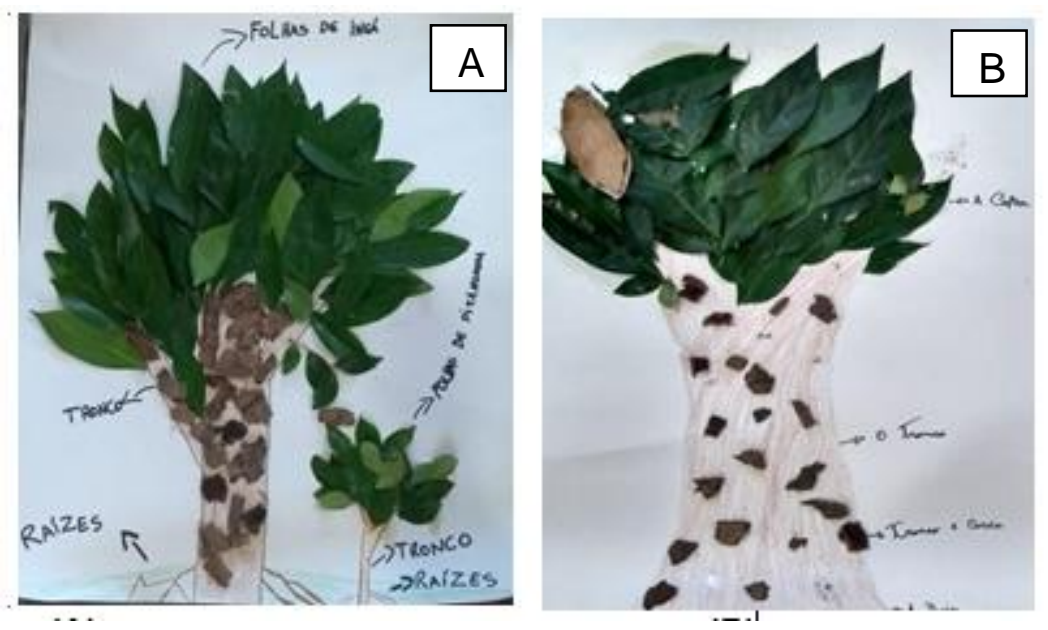

Figura 5: Confecção dos painéis arbóreos realizados pelos alunos do quarto ano do ensino fundamental. A) Representação em painel da espécie arbórea Ingá, com suas partes elementares identificadas. B) Representação em painel das espécies Ingá e Pitanga, ambas com suas partes identificadas. Fonte: Autoras (2019).

Ao final da atividade, distribui-se um questionário de seis (6) questões (ver em Santos, 2019) para cada participante responder individualmente, onde foi questionado sobre gostarem ou não da atividade, sendo que $100 \%$ dos alunos afirmaram que gostaram de realizar a atividade proposta.

Quando questionados sobre a situação da arborização na escola $15 \%$ respondeu que considera a escola muito arborizada, 54\% arborizada e 32\% responderam que a escola é pouco arborizada. Porém, quanto à importância que os alunos dão para a arborização na escola, 98\% afirmaram ser importante ter a escola arborizada, principalmente, destacando que elas seriam importantes por nos proporcionar sombra; oxigênio; ar; ou ainda por seu valor paisagístico (beleza), sendo que apenas um aluno mencionou a importância da arborização para o meio ambiente.

No estudo de Ávila et al. (2009) as respostas apresentam-se semelhantes no que se refere a importância das árvores na escola, sendo relatados os aspectos estéticos, ambientais e sociais delas, e também enfatizaram a importância de cuidar e preservar as árvores.

Ao final da confecção dos painéis os grupos apresentaram seus cartazes para os colegas, e em seguida realizou-se uma discussão em sala de aula, ressaltando os benefícios das florestas tanto para o ambiente como seus benefícios sociais e econômicos.

Desse modo, acredita-se que esta dinâmica contribuiu expressivamente para ampliar o conhecimento das crianças, pois demonstraram interesse em identificar as espécies arbóreas presentes no pátio da escola e representar o que haviam aprendido. 


\section{Levantamento das espécies no entorno da escola}

A atividade prática foi aplicada nas turmas do quinto ano do ensino fundamental, perfazendo um total de trinta e oito (38) alunos que participaram da atividade. Em um primeiro momento, em sala de aula, foi explicado, aos alunos como seria realizada a atividade na área do entorno da escola. Os alunos foram divididos em dois grupos, sendo cada grupo auxiliado por um responsável. Mesmo realizando a atividade na rua em frente, percebeu-se a motivação e entusiasmo dos alunos para a realização da prática.

A atividade proposta concentrou os grupos na rua em frente à escola, e devido a pouca diversidade de espécies arbóreas no local, o levantamento acabou sendo limitado na avaliação de alguns parâmetros sugeridos na ficha de avaliação, pois havia apenas indivíduos de extremosa (Lagerstroemia indica Pers.) e palmeira real (Archontophoenix cunninghamii H. Wendl. \& Drude).

Inicialmente foi realizada a identificação do primeiro indivíduo arbóreo juntamente com todos os alunos, com objetivo de sanar as principais dúvidas e curiosidades dos educandos, destacando para toda turma os pontos principais de análise que eles deveriam estar atentos para os demais indivíduos e o local em que situavam, facilitando assim o preenchimento da ficha do levantamento (ver em Santos, 2019).

As explicações para realização do levantamento de todos os quesitos solicitados seguiram conforme a ficha de campo. Foi possível observar já no levantamento do primeiro indivíduo arbóreo, o engajamento das crianças em participar das observações a serem feitas, como também nas medições solicitadas. Na sequência, os grupos realizaram a atividade prática do levantamento de todas as espécies arbóreas localizadas no entorno da escola.

Neste momento, buscou-se ressaltar algumas características e peculiaridades que os indivíduos apresentavam, também foi salientada a importância da arborização urbana para qualidade de vida de população e para o ambiente.

Esta dinâmica despertou tanto interesse dos alunos, que ao terminarem o levantamento arbóreo, sugeriram juntamente com a professora titular, em realizar futuramente a mesma atividade com as espécies arbóreas presentes no pátio da escola.

$\mathrm{Na}$ Figura $6 \mathrm{~A}$ observa-se os alunos do quinto ano realizando as medições da largura do calçamento, solicitadas na ficha. Na Figura 6B, nota-se os alunos realizando a medida da circunferência do tronco de um indivíduo da espécie Lagerstroemia indica (L.) Pers, em frente à escola. 


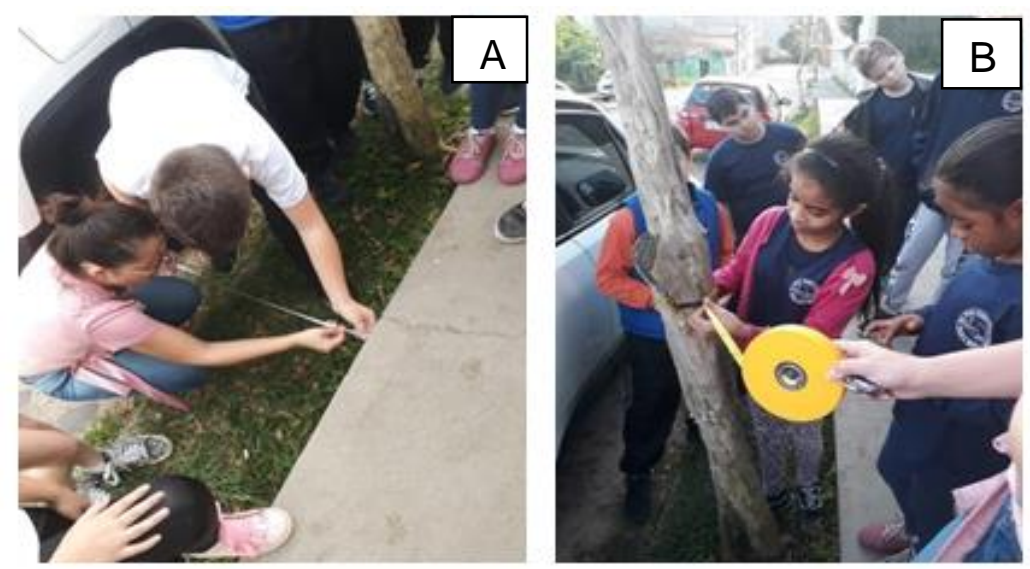

Figura 6: Atividade prática de levantamento das espécies arbóreas localizadas no entorno da escola, com os alunos do quinto ano do ensino fundamental. Fonte: Autoras (2019).

Ao final da atividade as crianças retornaram para a sala de aula, onde cada uma recebeu um questionário de sete (7) questões (ver em Santos, 2019) para responder individualmente. As questões foram voltadas para compreender a percepção dos alunos quanto à atividade proposta. Assim, estes foram questionados, por exemplo, sobre gostar ou não de realizar a atividade de levantamento das espécies florestais na rua da sua escola, sendo que $100 \%$ deles responderam sim.

No entanto, quando questionados o porquê que gostaram de realizar a atividade, $37 \%$ dos alunos deram destaque ao aprendizado, ao responderem: "aprendi coisas que nem fazia ideia; aprendi mais sobre as árvores; aprendi coisas novas; aprendi muitas coisas sobre as árvores e as medir; aprendi um pouco mais; porque aprendemos e nós adoramos trabalhar em grupo; aprender algo novo é legal".

Observou-se que $32 \%$ das crianças voltaram suas repostas ao sentimento de alegria ao realizar a atividade quando responderam que: "foi legal medir e conhecê-las; achei muito legal ver e analisar as árvores; bem legal ter esse tempinho com a natureza; gostei porque a gente interage com as coisas; adorei essa atividade".

Porém, $11 \%$ dos participantes deram destaque sobre as medições propostas na atividade, enfatizando o quanto adoraram realizar essa prática, ao responderem que: "eu adorei medir; eu aprendi a medir as árvores, porque a gente se ajudou a medir as árvores", etc. Cerca de $11 \%$ dos alunos atribuíram a atividade a importância de saber mais sobre as árvores e plantas, e os demais alunos (10\%) salientaram sobre a relevância de atividades ao ar livre, diferentes do que já tinham realizado. De acordo com Cocito (2016) ao propiciar para as crianças espaços em contato com a natureza, permitimos que elas ampliem sua relação homem/natureza, e assim aprendendo a preservar e valorizar o meio em que vive.

Diante disso, observou-se a importância em promover atividades diferentes das do cotidiano escolar, com a proposta, pois proporcionou às 
crianças a terem contato com a natureza, e oportunizou os alunos realizarem atividades que talvez só viessem a praticar se no futuro, cursarem um curso técnico ou uma graduação na área.

Ainda foi possível observar as informações atribuídas pelas crianças quando questionadas sobre quais das informações medidas e coletadas que acharam difícil de realizar no levantamento a campo.

Observou-se que os três maiores valores em percentagem foram relacionados com as avaliações de campo que demandam de um conhecimento mais técnico e específico, como por exemplo, dendrologia (identificação das espécies, verificar se são nativas/exóticas), dendrometria (medição de altura das árvores, da copa), fitopatologia (doenças, pragas), botânica (morfologia, classificação identificação, reprodução).

Nesta análise, vinte e um por cento (21\%) dos educandos responderam que a maior dificuldade que eles encontraram na atividade foi saber identificar se a árvore é nativa e exótica, $20 \%$ relataram ter dificuldade em identificar se havia alguma doença ou praga, $12 \%$ dos participantes atribuíram a dificuldade em identificar se havia danos nas árvores e também na execução de medir a altura das árvores. Por fim, $8 \%$ dos participantes consideraram a medição da copa da árvore, a medida mais difícil de ser realizada.

Neste contexto, Córdula (2009) ressalta a importância das atividades práticas, pois permitem à união, cooperação, a socialização do aluno, como também promove o aprendizado, estimulando o crescimento intelectual do educando. Sendo assim, as atividades práticas geram a sensibilização necessária nas crianças para torná-las aptas a difundirem seus conhecimentos adquiridos na escola com a comunidade em geral.

Ainda foi apresentada a percepção (em percentagem) do que as crianças do quinto ano consideraram importante aprender com o levantamento arbóreo. Nota-se que $17 \%$ deles, responderam sobre a importância de aprender e saber que existem diferentes tipos de espécies arbóreas.

Outro destaque relevante é que $17 \%$ dos alunos responderam ser importante saber que não se pode plantar qualquer tipo de árvore na calçada. Ao analisar esse dado, percebeu-se a importância da atividade ao proporcionar esse conhecimento as crianças, a qual os alerta para algumas questões sobre a arborização urbana, como por exemplo, os cuidados que se devem ter na escolha de uma espécie mais adequada a ser plantada na calçada.

Ao transmitir esse conhecimento as crianças, procurou-se fortalecer a compreensão sobre como as diferentes áreas das ciências florestais estão presentes no nosso cotidiano, buscando também, potencializar a capacidade de uma visão mais crítica e construtiva das crianças para este setor, as quais poderão no futuro fazer parte de um órgão de gestão, ou serem participantes de associações de moradores, os quais poderão discutir essas questões com os gestores urbanos, trazendo a médio e longo prazo benefícios às cidades e ao meio ambiente. 
Apesar da grande aceitação por parte dos alunos e professores que participaram do projeto, infelizmente, observamos que poucas são as atividades de educação ambiental que dão ênfase às questões florestais, sendo uma área pouco explorada nos projetos de educação ambiental. Contudo, os resultados adquiridos neste trabalho demostraram a importância de inserirmos os temas relacionados aos recursos florestais nas turmas do ensino fundamental, as quais estão iniciando seus estudos e compreensões sobre o meio ambiente e os possíveis impactos que o cercam, fortalecendo ainda mais a construção de uma sociedade ambientalmente consciente e sustentável.

Neste contexto, ao serem indagados se gostariam de realizar mais atividades práticas como esta, que destaca a importância das árvores, das florestas e dos recursos florestais como um todo, obteve-se $100 \%$ de aceitação, ou seja, todos os alunos do quinto ano afirmaram que gostariam de realizar mais atividades como a proposta.

Logo, cabe destacar que a escola ao propiciar atividades ao ar livre, possibilitando o contato com a natureza para os alunos explorarem, brincarem, pode colaborar na construção de valores, regras e cuidados com o meio ambiente que poderá acompanhar todo o período de desenvolvimento da criança, pois, quanto mais cedo eles entenderem e se sensibilizarem sobre a importância e valorização dos recursos naturais, mais cedo poder-se-á iniciar o processo de construção do pensamento crítico e reflexivo sobre o meio em que vivemos.

Ao término desta atividade foi solicitado aos alunos que demostrassem na forma de desenho o seu entendimento a respeito da dinâmica de campo (Figura 7). Observa-se na Figura 7A em que o aluno buscou representar como foram realizadas as leituras (medições) das alturas das árvores, já na Figura 7B a criança expressou a prática de medir a distância entre indivíduos arbóreos.
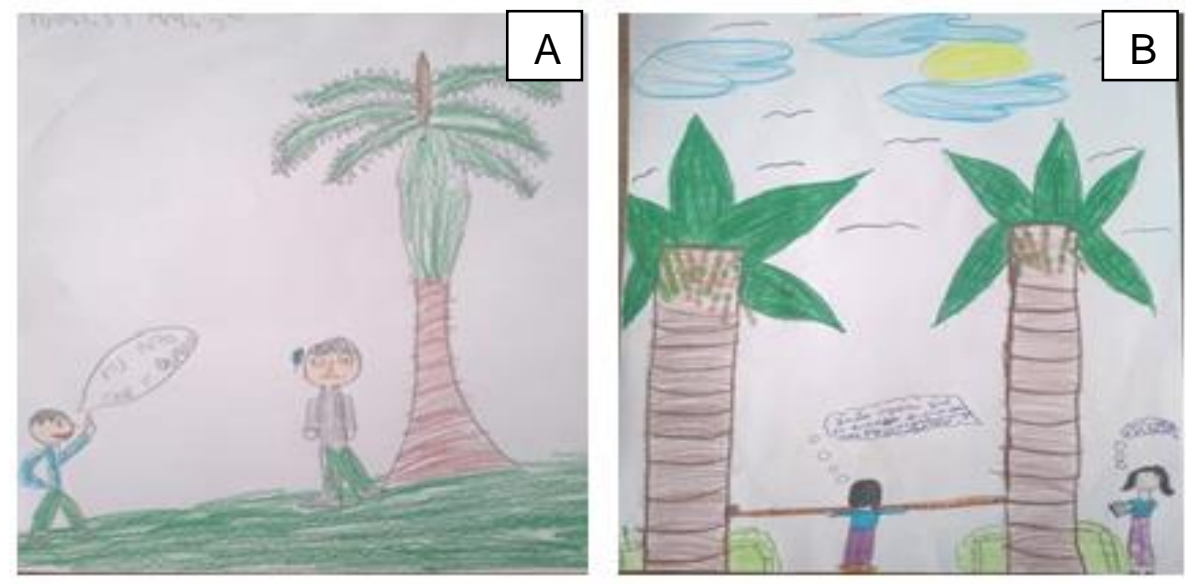

Figura 7: Exemplo de ilustração realizada pelos alunos do quinto ano do ensino fundamental da atividade do levantamento das espécies arbóreas localizadas no entorno da escola. A) llustração da prática de medir a altura dos indivíduos arbóreos. B) llustração da prática de medir a distância entre árvores. Fonte: Autoras (2019). 
Percebeu-se que tanto no questionário quanto nas ilustrações, as crianças expressaram sentimentos positivos a respeito da aula prática, sendo um resultado coerente, devido às sensações que expressaram oralmente, proporcionadas pelo ambiente e principalmente pelo fato de realizarem uma atividade diferente do cotidiano escolar.

Nesse sentido, reforça a relevância deste estudo, em razão de propiciar aos participantes o contato com o ambiente natural, permitindo a integração entre os sentidos, e sentimentos dos alunos, quando vivenciam, tocam, sentem, praticam e não apenas imaginam situações, realidades, como por vezes ocorre em sala de aula.

\section{Pesquisa qualitativa com os educadores}

Participaram da pesquisa os professores das turmas do primeiro ao quinto ano do ensino fundamental, que participaram do presente estudo. A pesquisa foi realizada por meio de um questionário contendo nove (9) questões (ver em Santos, 2019).

Os questionários foram entregues a cada início de aula e recolhido ao final da aula, todos os nove (9) professores avaliados tem formação superior, especialização ou pós-graduação na área da pedagogia, e ou psicopedagogia, sendo que apenas, uma professora tem especialização na área da educação ambiental.

Quando questionados sobre se a escola possuía alguma atividade ou projeto (exceto este), que visa discutir e trabalhar com os alunos as questões voltadas à conservação ambiental ou a educação ambiental/florestal, $78 \%$ afirmaram que sim, tendo relatado pelos educadores que este ano o tema meio ambiente foi trabalhado do nível pré-escola até $0 \quad 4^{\circ}$ ano, pois é uma preocupação dos educadores que esse assunto seja sempre desenvolvido em sala de aula. Alguns professores relataram também terem escolhido este tema para aplicação de projeto em sala. Porém, $22 \%$ dos professores afirmaram que no momento não havia atividades com essa temática sendo aplicado em suas turmas.

Quando indagados sobre a metodologia utilizada na atividade aplicada com os alunos, $78 \%$ avaliaram como ótimo, destacando que o tema e a metodologia atenderam o esperado e $22 \%$ descreverem como sendo boa da forma como foi aplicada a atividade. Quanto às justificativas relatadas, todas foram positivas referentes às dinâmicas aplicadas, como pôde-se observar nas respostas apresentadas: "muito importante o tema e a maneira como foi introduzido também", "as crianças adoraram as caixas sensoriais"; "acredito que a maneira como a atividade foi aplicada atraiu a atenção e interesse dos alunos"; "os alunos mantiveram se atentos e motivados e que demonstra ter sido significativo para eles".

Outro dado interessante avaliado foi que todos os professores (100\%) afirmaram que trabalham alguns temas relacionados com a questão florestal ou 
ambiental, ou desenvolve práticas de EA em suas aulas, corroborando com estudo descrito por Lima (2004), o qual destaca que o âmbito escolar é um espaço privilegiado para estabelecer informações e conexões, como também é um meio de instigar os educandos a ter concepções e responsabilidades como o meio que integram.

Em relação, a frequência que esses assuntos são abordados em sala de aula $67 \%$ dos professores responderam que às vezes tratam sobre o assunto em sala, sendo os principais temas mencionados: problemas gerados pelo descarte de resíduos; reciclagem; consumo consciente da água; sustentabilidade; o homem e o meio ambiente; tipos de biomas do RS e preservação de biomas. Já os $33 \%$ restantes, relataram que sempre são abordados assuntos referentes à temática geral.

Ao analisar as considerações apresentadas pelos professores do ensino fundamental, percebeu-se o quanto é crucial que sejam trabalhadas distintas temáticas que envolvem os recursos florestais como, por exemplo, a riqueza dos produtos e subprodutos oriundos das florestas nativas e exóticas, o manejo e o uso racional da floresta, a importância da conservação e do uso sustentável dos recursos naturais, e outras áreas de conhecimento da engenharia florestal.

Isso porque, ao fazermos uma análise crítica sobre as atividades de EA aplicadas no âmbito escolar, observamos que a maioria destas estão limitada a temas como resíduos ou preservação do ambiente de um modo geral, mas raramente se abordam questões sobre a valorização dos recursos florestais, os produtos e benefícios ambientais, sociais e econômicos que estes nos geram, o que acaba por enaltecer a pertinência desse estudo, em apresentar as crianças assuntos que muitas vezes não estão presentes na sua grade curricular.

\section{Considerações Finais}

Ao findar este trabalho, temos a certeza que o grande envolvimento dos educandos e professores durante as oficinas temáticas, as dinâmicas assistidas, e as práticas de campo contribuíram positivamente na sensibilização dos participantes, alcançando assim com os objetivos propostos.

Nesse estudo ficou claro que a inserção da temática valorização dos recursos florestais nas práticas de educação ambiental, juntamente com as atividades lúdicas, são ferramentas que estimulam e incentivam as crianças a pensar e agir de uma forma reflexiva e dinâmica, socializando os assuntos aprendidos dentro e fora do ambiente escolar.

Destaca-se que as atividades apresentadas, sejam apenas uma pequena fração em relação às possibilidades que podem ser oferecidas, e sirvam como estímulo por mais estudos e dinâmicas voltados à valorização das nossas florestas no âmbito escolar, oportunizando as crianças um maior 
contato e conhecimento sobre os inúmeros benefícios oriundos dos recursos naturais.

O trabalho trouxe ainda uma reflexão do papel do engenheiro florestal nas ações de educação ambiental, uma vez que a maioria dos profissionais acaba por atuar em outras áreas sem compreender que todas elas podem de alguma forma ser inseridas no contexto da educação ambiental, quebrando assim paradigmas quanto à atuação desse profissional.

Este estudo demostrou que é possível o engenheiro florestal trabalhar a importância dos recursos florestais por meio da educação ambiental, levando a extensão como a principal ferramenta para expor a sociedade os benefícios das florestas, assim como seus produtos e subprodutos presentes no nosso dia a dia.

É de extrema importância que estas e outras atividades de extensão, que apresentem conteúdos voltados à valorização dos recursos florestais, tenham a oportunidade de serem implementadas no cotidiano escolar das crianças, pois no momento que aproximamos o conhecimento e a tecnologia desenvolvidos nas universidades, toda sociedade e ambiente é beneficiada.

\section{Agradecimentos}

Á Escola Municipal de Ensino Fundamental Padre Nóbrega por todo seu corpo docente e discente por permitirem a execução do presente estudo.

\section{Referências}

ÁVILA, A. L. de; et al. Educação Ambiental no ensino fundamental através da identificação e plantio de espécies arbóreas. Revista Eletrônica do Mestrado em Educação Ambiental, v. 22, jan./jul., 2009.

COCITO, R. P. A natureza como espaço educacional: oportunidades para a infância. Colloquium Humanarum. v. 13, n. especial, p. 94-100, jul/dez, 2016.

CÓRDULA, E.B.L. Educação Ambiental Integradora (EAl): Unindo saberes em prol da consciência ambiental sobre a problemática do lixo. Revista Brasileira de Educação Ambiental. p. 96-103. 2009.

EFFTING, T. R. Educação Ambiental nas Escolas Públicas: realidade e desafios. 2007. 90 f. Monografia (Pós-graduação em "Latu Sensu" Planejamento Para o Desenvolvimento Sustentável) - Centro de Ciências Agrárias, Universidade Estadual do Oeste do Paraná, Campus Marechal Cândido Rondon, 2007. Disponível em: <http://ambiental.adv.br/ufvjm/ea20121monografia2.pdf>. Acesso em: 28 dez. 2018.

JUNIOR, N. M.; S. L. A. dos; J. L. M. S. de. Educação Ambiental: concepções e práticas pedagógicas de professores do ensino fundamental da rede pública e privada em Itabaiana, Sergipe. Rev. Eletrônica Mestr. Educ. Ambient., v. especial, p. 213-236, jul./dez., 2016. 
LIMA, W. Aprendizagem e classificação social: um desafio aos conceitos. Fórum Crítico da Educação: Revista do ISEP/Programa de Mestrado em Ciências Pedagógicas, v. 3, n. 1, out, 2004.

MATAREZI, J. Trilha da vida: (re)descobrindo a natureza com os sentidos. Ambiente \& Educação. Revista de Educação Ambiental da FURG, Rio Grande (RS): Fundação Universidade do Rio Grande, v. 5/6, p. 55-67, 2000/2001.

MEDEIROS, A. B.; et al. Importância da Educação Ambiental na escola nas séries iniciais. Rev. Faculdade Montes Belos, v. 4, n. 1, 2011.

MORIN, E. A Cabeça bem-feita: Repensar a Reforma Reformar o Pensamento. 14. ed. Ed. Bertrand Brasil, Rio de Janeiro: RJ, 2008.

OLIVEIRA, A. U. Situação e tendências da Geografia. In: OLIVEIRA, A. U. (org.). Para onde vai o ensino de Geografia? 7. Ed. São Paulo: Contexto, p. 24-29, 1998.

PASQUALETTO, A.; MELO, E. L.; Trilha Sensitiva no Memorial do Cerrado da Universidade Católica de Goiás. Revista Eletrônica do Mestrado em Educação Ambiental. Rio Grande. v.18, jan./jun. 2007.

PFEIFER, F. J.; et al. A trilha sensitiva como prática de Educação Ambiental para alunos de uma escola de ensino fundamental de Palmeira das MissõesRS. Revista Eletrônica do Mestrado em Educação Ambiental, v. especial, p. 64-84, jul./dez. 2016.

PIAGET, J. Psicologia e Pedagogia. Rio de Janeiro: Forense Universitária, 1982.

RAMBO, G. C.; ROESLER M. R. V. B. Vivência com a natureza no ambiente escolar na primeira infância e sua relevância para construção do respeito e cuidados com o meio ambiente. Revista Brasileira de Educação Ambiental, São Paulo, v. 14, n. 1, p. 111-131. 2019.

SANTOS, M. M. Dinâmicas de Educação Ambiental para valorização dos Recursos Florestais aplicadas ao Ensino Fundamental. 2019. 70 f. Trabalho de Conclusão de Curso - Universidade Federal de Santa Maria, Santa Maria, 2019.

SILVA, D. G. A importância da Educação Ambiental para a sustentabilidade. FAFIPA, São Joaquim - PR. 2012 Disponível em: <http://www.uniedu.sed.sc.gov.br/wpcontent/uploads/2014/04/DANISE-

GUIMARAES-DA-SILVA.pdf>. Acesso em 28 de jan. 2019.

VYGOTSKY, L. S. Problemas de método. In: VYGOTSKY, L. S. A formação social da mente. 3. Ed. São Paulo Martins Fontes, 1989. 